\title{
Nowe funkcje zasilaczy inwertorowych zbudowanych techniką MICOR do metody MMA
}

\section{New features of the MMA welding inverter built in MICOR technology}

\section{Streszczenie}

W artykule przedstawiono wyniki badań doświadczalnych właściwości użytkowych nowoczesnego spawalniczego źródła inwertorowego wykonanego w technice MICOR. Różni się ono od klasycznego zasilacza z przemianą częstotliwości tym, że po stronie pierwotnej zastosowano dwa falowniki oraz dwa transformatory wysokiej częstotliwości połączone w jeden układ elektryczny. Zaprezentowano zewnętrzne charakterystyki statyczne i dynamiczne oraz wybrane właściwości spoin.

\section{Wstęp}

Jedną z podstawowych metod łączenia metali jest nadal ręczne spawanie elektrodą otuloną. Metoda ta wykorzystywana jest zarówno w zastosowaniach amatorskich, jak i w produkcji spawalniczej-na montażu, jak i do wysokowydajnego spawania, w tym do napawania i modyfikacji powierzchni $[1 \div 5]$. W artykule przedstawiono m.in. zastosowanie nowych funkcji wbudowanych w systemy sterowania nowoczesnych urządzeń spawalniczych, przeznaczonych do spawania metodą MMA w technice MICOR. Funkcje te wykorzystywane są podczas spawania elektrodami z zastosowaniem impulsowej modulacji prądu, która zmniejsza odkształcenia materiału, dając lepszy komfort pracy spawacza przy jednoczesnym podwyższeniu jakości złączy spawanych i wydajności procesu.

Dr hab. inż. Tomasz Chmielewski - Politechnika Warszawska, dr inż. Marek Węglowski - Rywal-RHC, Warszawa, dr inż. Krzysztof Kudła-Politechnika Częstochowska.

\section{Przekształtniki z wewnętrzną przemianą częstotliwości}

Zasilacze łuku spawalniczego nowej generacji, do której należą przekształtniki z wewnętrzną przemianą częstotliwości po stronie pierwotnej transformatora, zwane inwertorami lub zasilaczami inwersyjnymi, funkcjonują od blisko 30 lat. Budowa tego typu zasilaczy stała się możliwa dzięki zastosowaniu w urządzeniach spawalniczych tranzystorów o dużej mocy i wysokim dopuszczalnym napięciu obciążenia. Inwertorowe spawalnicze źródła energii budowano według nowych zasad działania. Konstrukcyjnie różniły się one od zasilaczy łuku spawalniczego opartych na prostownikach diodowych lub tyrystorowych $[6 \div 9,12,13]$.

Schemat blokowy przekształtnika $\mathrm{z}$ wewnętrzną przemianą częstotliwości po stronie pierwotnej pokazano na rysunku 1 . Składa się on z następujących głównych zespołów:

- prostownika napięcia sieci zasilającej jedno- lub trójfazowego (1), 
- filtra pojemnościowego napięcia wyprostowanego (2),

- falownika tranzystorowego (3),

- transformatora podwyższonej częstotliwości (4),

- prostownika wtórnego podwyższonej częstotliwości (5),

- dławika filtrującego (6).

Zastosowany w przekształtniku sterownik zawiera układy regulacji i spełnia wszystkie funkcje sterowania i kontroli pracy falownika, tzn.:

- generuje impulsy o częstotliwości i szerokości wynikającej z nastawionego natężenia prądu spawania lub programu zmian tego prądu,

- zamienia sygnał zadany prądu spawania na odpowiednie sygnały sterujące pracą generatora wraz z układami logiki systemu sterowania pracą falownika;

- kontroluje równocześnie minimalną i maksymalną szerokość impulsów,

- kontroluje prąd tranzystorów w układzie falownika,

- kontroluje temperaturę elementów podatnych na przeciążenia prądowe,

- kontroluje napięcie zasilania,

- wypełnia wiele innych funkcji związanych ze sterowaniem i kontrolą pracy falownika.

Zastosowany w układzie sterowania regulator spełnia wszystkie funkcje związane z zadawaniem, regulacją i sterowaniem pracą przekształtnika i procesu spawania, tzn.:

- zadaje wartość podstawowego parametru spawania,

- optymalizuje wartości prądu spawania,

- optymalizuje charakterystyki przy załączeniu falownika,

- przełącza parametry spawania,

- wytwarza impulsy modulujące prąd spawania (przy spawaniu prądem pulsującym),

- diagnozuje i wyłącza awaryjnie obwody,

- kontroluje obieg cieczy chłodzącej palnika spawalniczego,

- zadaje wstępne parametry spawania,

- włącza układy pomiarowe oraz wypełnia wiele innych funkcji.

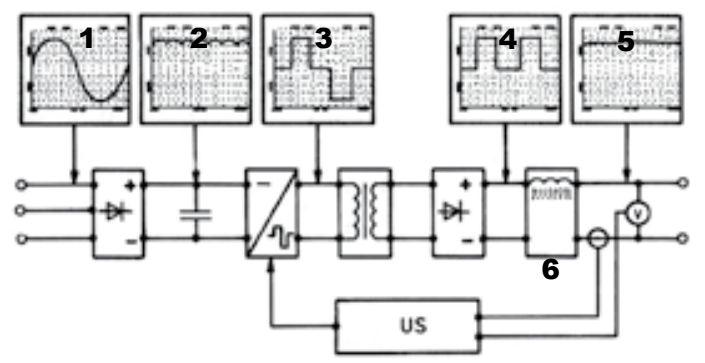

Rys. 1. Schemat blokowy przekształtnika z wewnętrzną przemianą częstotliwości po stronie pierwotnej; US - układ sterowania, regulacji i zabezpieczeń [8]

Fig. 1. Block diagram of the converter with internal conversion of frequency on the primary side; U.S. - the control unit and electrical protection system

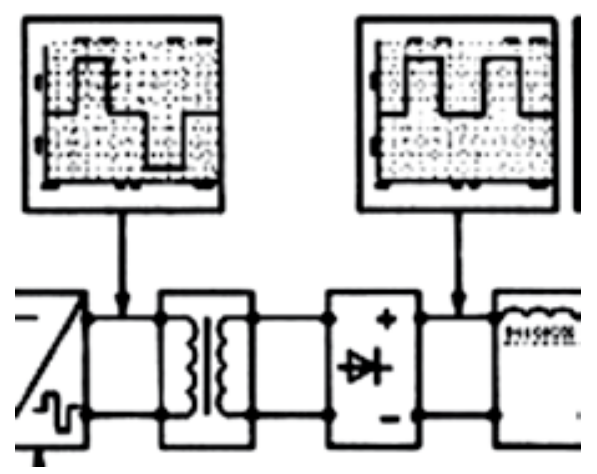

Rys. 2. Część schematu przekształtnika z wewnętrzną przemianą częstotliwości, która w technice MICOR ma odmienną budowę

Fig. 2. Part of block scheme of the converter with internal conversion of frequency, with a different structure in the MICOR technology

Już pod koniec lat 80. ub. w. opublikowano artykuły dotyczące nowoczesnych źródeł inwertorowych wyko-

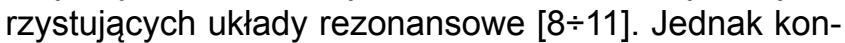
strukcje tego typu były głównie teoretyczne, ponieważ poziom technologiczny w tamtym czasie był niewystarczający do ich zastosowania na skalę produkcyjną. W 2005 r. firma Lorch przedstawiła i opatentowała

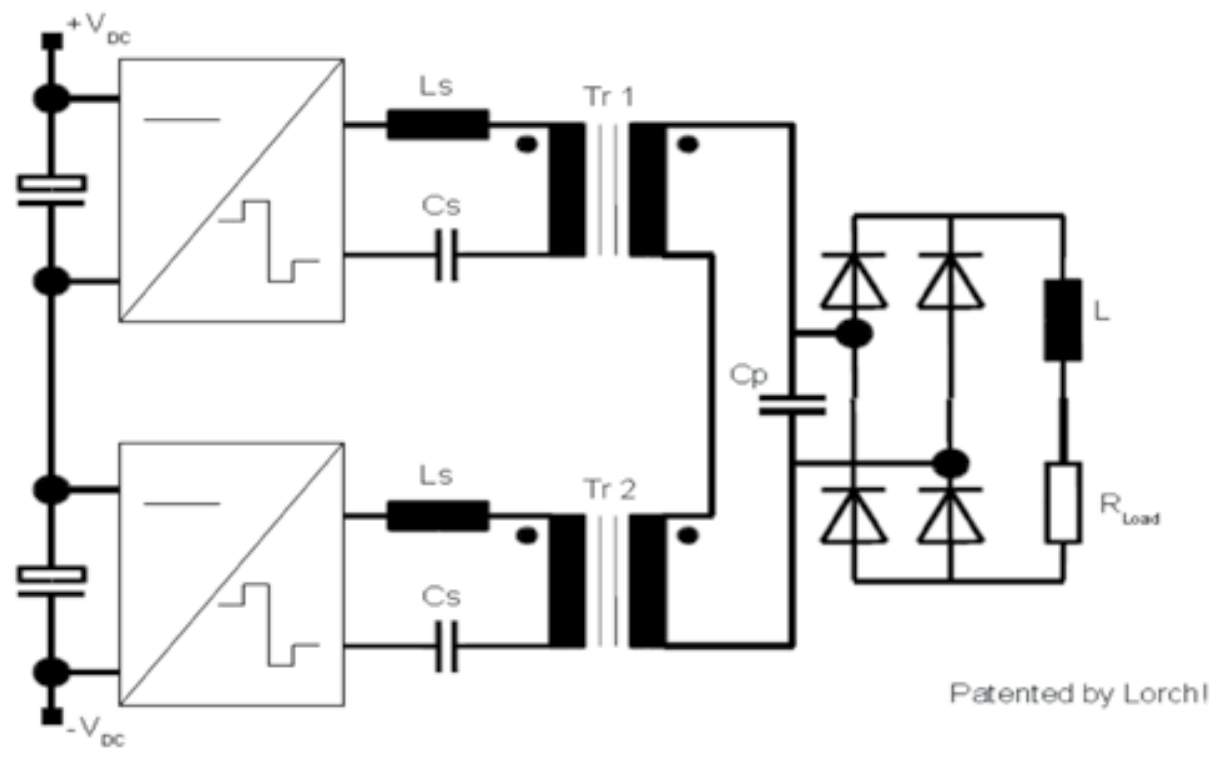

Rys. 3. Schemat blokowy przekształtnika z wewnętrzną przemianą częstotliwości w technice MICOR

Fig. 3. Block diagram of the converter with internal conversion of frequency based on the MICOR technology 
swoje rozwiązanie pod nazwą Superresonant Series-Parallel Bridge Converter, wykonane w technice MICOR. Schemat blokowy układu jest podobny do schematu pokazanego na rysunku 1. Różnica dotyczy jedynie części schematu, który pokazano na rysunku 2.

Na rysunku 3 przedstawiono schemat ideowy źródła inwertorowego wykonanego w technice MICOR. Różnice w stosunku do klasycznego zasilacza z przemianą częstotliwości po stronie pierwotnej są następujące: po stronie pierwotnej zastosowano dwa falowniki oraz dwa transformatory wysokiej częstotliwości połączone w jeden układ elektryczny $[14,15]$. Przez wiele lat różne firmy próbowały połączyć ze sobą dwa niezależne falowniki tak, aby pracowały synchronicznie. Rozwiązanie takie zastosowała i opatentowała firma Lorch [20]. Następną różnicę stanowi zastosowanie między falownikiem i przed transformatorem cewki wysokiej częstotliwości $L_{s}$ oraz kondensatora $C_{s}$, które razem $z$ transformatorem tworzą układ rezonansowy.

Napięcie przechodzące przez cewkę jest indukowane i podwyższane. Zastosowanie kondensatora o odpowiedniej pojemności powoduje magazynowanie ładunku, a po naładowaniu kondensatora procesor wyłącza falownik, czego skutkiem jest rozładowanie kondensatora. Dzięki temu urządzenia inwertorowe zbudowane w technice MICOR mają odpowiednio duży zapas napięcia, dający stabilny łuk niewrażliwy na zakłócenia powstające podczas spawania. Zmiana konstrukcji wewnętrznej urządzenia spowodowała zdecydowany spadek masy urządzeń. Przykładowo, masa urządzenia $350 \div 400$ A wynosi $18 \mathrm{~kg}$, czyli o ponad połowę mniej niż w klasycznych zasilaczach inwertorowych.

\section{Zewnętrzne charakterystyki statyczne badanych źródeł prądowych}

Zewnętrzna charakterystyka statyczna spawalniczego źródła zasilania przedstawia zależność napięcia mierzonego na zaciskach wyjściowych źródła w funkcji prądu płynącego $\mathrm{w}$ obwodzie zewnętrznym $\mathrm{w}$ warunkach rezystancyjnego obciążenia symulującego łuk spawalniczy.

Badaniom poddano klasyczne źródło inwertorowe prądowe - Most Ponte 165 oraz zasilacz inwertorowy wykonany techniką MICOR - X350 Lorch. Wyniki pomiarów statycznych charakterystyk klasycznych zasilacza inwertorowego przedstawiono na rysunku 4,

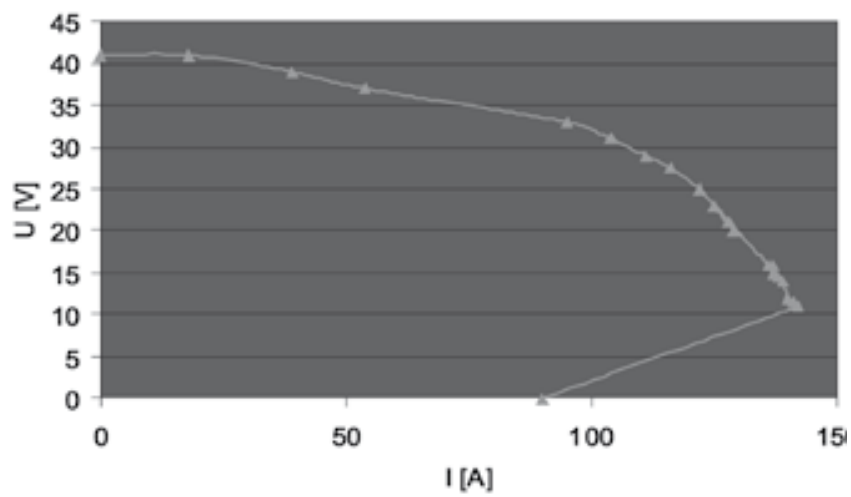

Rys. 4. Charakterystyka zewnętrzna statyczna źródła klasycznego inwertorowego MOST Ponte 165

Fig. 4. External static characteristic of the classical welding inverter MOST Ponte 165

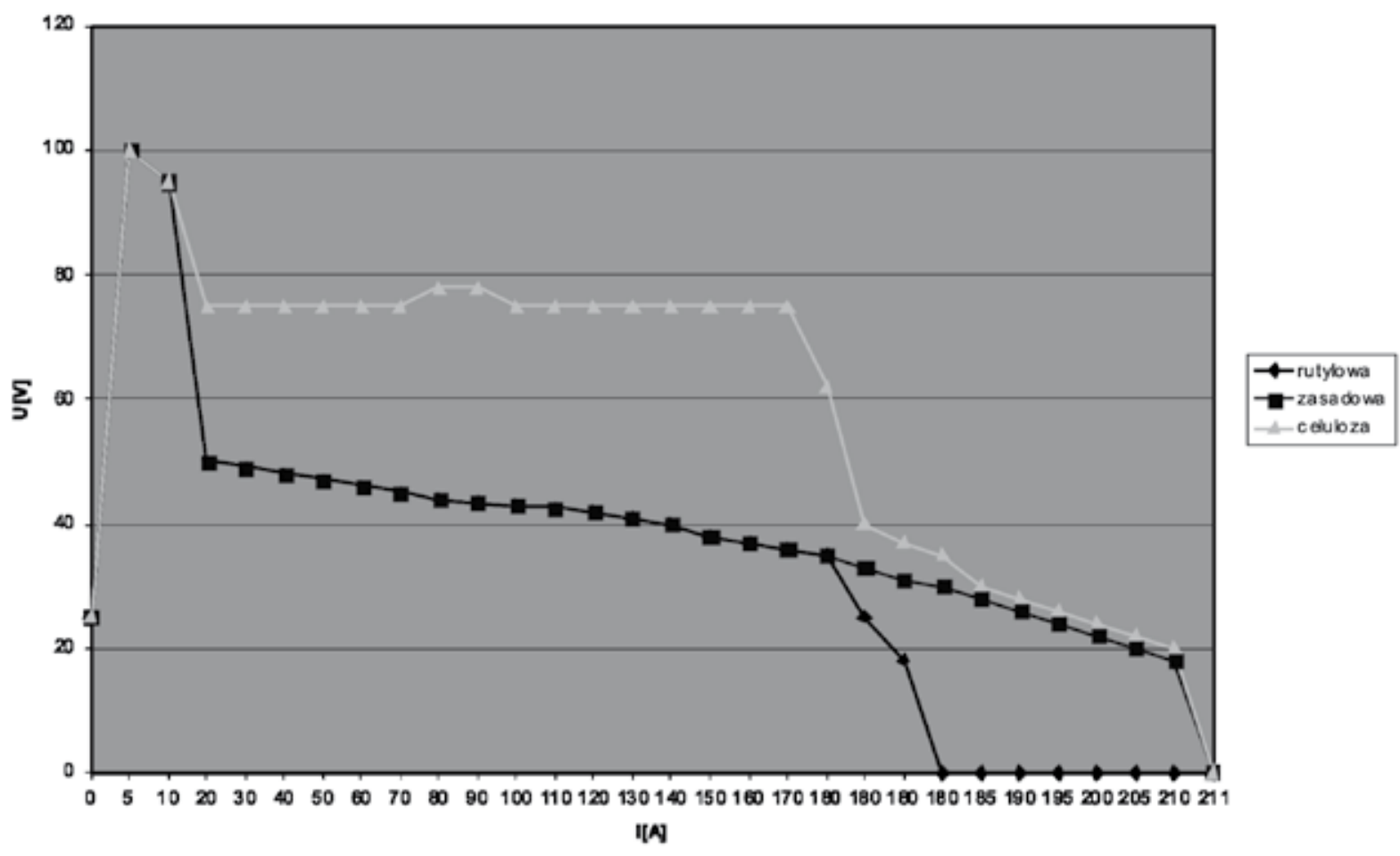

Rys. 5. Charakterystyki zewnętrzne statyczne źródła inwertorowego X-350 Lorch wykonanego techniką MICOR

Fig. 5. External static characteristics of the modern welding inverter X-350 Lorch based on the MICOR technology 
natomiast na rysunku 5 pokazano charakterystyki zewnętrzne statyczne źródła MICOR.

Ważną zaletą źródeł prądowych wykonanych techniką MICOR jest zabezpieczenie spawacza przed porażeniem prądem przez zastosowanie niskiego napięcia spoczynkowego (stand by voltage) na poziomie $24 \mathrm{~V}$. Jednocześnie zastosowanie wysokiej wartości napięcia stanu jałowego, na dopuszczalnym poziomie osiągającym nawet $100 \mathrm{~V}$, powoduje silne zjonizowanie przestrzeni międzyelektrodowej, czego efektem jest wysoka stabilność łuku, przy braku trwałych zwarć elektrody, oraz polepszenie ponownych zapłonów łuku spowodowanych m.in. spawaniem w pozycjach przymusowych lub niewłaściwym osuszeniem i niską jakością elektrod [19].

Dzięki zastosowaniu wysokiego napięcia w obszarze niskiego natężenia prądu spawania uzyskuje się wysoką elastyczność łuku, szczególnie podczas dużych wahań jego długości spowodowanych między innymi zmianą pozycji spawania, geometrią rowka czy nawet niskimi umiejętnościami spawacza. Takie rozwiązanie zapobiega wygaszaniu łuku przy dużej zmienności napięcia spawania oraz daje lepszy komfort pracy spawacza związany z niezakłóconym wykonywaniem ściegu spoiny.

W źródłach zbudowanych techniką MICOR istnieje możliwość przełączenia na tryb spawania elektrodami rutylowymi, elektrodami zasadowymi i celulozowymi (rys. 5). W przypadku spawania elektrodami zasadowymi wykorzystuje się charakterystykę statyczną zewnętrzną z funkcją Force Arc, zwiększającą natężenie prądu w czasie znacznego obniżenia napięcia łuku podczas jego skrócenia lub zwarcia kropli ciekłego metalu z jeziorkiem spawalniczym. Wzrost prądu powoduje krótkotrwałe zwiększenie siły elektrodynamicznej i szybkie odcięcie kropli od końca elektrody. W przypadku spawania elektrodami celulozowymi napięcie na odcinku poziomym charakterystyki utrzymywane jest na wysokim poziomie ok. 70 V. Zapobiega to wygaszeniu łuku przy znacznym jego wydłużeniu, co jest charakterystyczne dla spawania $z$ użyciem tego typu elektrod. W punkcie pracy charakterystyka statyczna jest stałoprądowa również z dodatkową funkcją Force Arc. Dzięki zastosowaniu innowacyjnych rozwiązań w urządzeniach budowaną techniką MICOR możliwe jest zastosowanie dużej rezerwy napięcia, przy jednoczesnym zmniejszeniu o ponad połowę masy urządzenia w stosunku do klasycznych zasilaczy inwertorowych.

\section{Zewnętrzne charakterystyki dynamiczne zasilaczy}

Celem określenia dynamicznych właściwości nowej generacji zasilaczy budowanych techniką MICOR, przeprowadzono próby spawania $z$ jednoczesną rejestracją prądu spawania i napięcia łuku przy różnych nastawach parametrów oraz funkcji sterowania.

Dla każdego urządzenia i każdej nastawy natężenia prądu wykonano 10 prób spawania, a do dalszej analizy wybrano najbardziej typowe dla każdego przypadku spoiny i przyporządkowany im czasowy przebieg prądu i napięcia spawania (oscylogram). Zarejestrowane podczas badań oscylogramy przedstawiono w tablicy I.

Na podstawie badań przebiegów czasowych prądu i napięcia spawania stwierdzono, że sposób przechodzenia kropli ciekłego metalu ma charakter zwarciowy, niezależnie od rodzaju badanego inwertora.

Znaczne różnice występują w charakterze czasowych przebiegów parametrów, głównie prądu spawania. Porównując klasyczne źródło inwertorowe Most Ponte 165 z urządzeniem X 350 firmy Lorch w funkcji spawania normal, można zauważyć różnice w przebiegach prądowo-czasowych. W źródle klasycznym podczas zwarcia ciekłej kropli elektrody z materiałem prąd bardzo szybko narasta do wartości maksymalnej prądu zwarcia, która jest utrzymywana aż do momentu oderwania się kropli od elektrody, po czym natężenie prądu opada bardzo szybko do wartości roboczej. W źródle MICOR w procedurze spawania normal przebieg prądu podczas zwarcia składa się z dwóch faz. W pierwszej występuje krótkotrwały pik prądowy mający za zadanie przygotowanie (podgrzanie) końca elektrody do utworzenia i odcięcia kropli, co następuje w drugiej fazie zwarcia. Takie podejście stwarza lepsze warunki spawania związane z kontrolowanym transportem ciekłego metalu do jeziorka. Opisane rozwiązanie nie jest spotykane w klasycznych źródłach inwertorowych. W technice MICOR uzyskanie tak dynamicznych zmian prądowych możliwe jest dzięki zastosowaniu bardzo szybkich procesorów, mierzących napięcie łuku, i odpowiednio zaprogramowanej procedury spawania - źródło odpowiednio reaguje na zakłócenia, wydłużając lub skracając poszczególny etapy przechodzenia kropli.

Dodatkowo w celu ułatwienia spawania w pozycjach przymusowych wprowadzono w urządzeniach dodatkową funkcję spawania impulsowego, które do tej pory nie było stosowane w metodzie MMA. W tablicy I przedstawiono przebiegi czasowe prądu, którego zmiany odbywają się cyklicznie z poziomu prądu spawania 100 do $50 \mathrm{~A}$, zmniejszając efektywnie ciepło wprowadzone do złącza, ograniczając jednocześnie odkształcenia i płynność jeziorka, co zapobiega spływaniu ciekłego metalu, szczególnie podczas spawania w pozycji PF.

\section{Wybrane właściwości spoin}

Przeprowadzono badania metalograficzne wybranych spoin. Na rysunkach 6 i 8 pokazano powierzchnie lica spoin. Rysunek 7 przedstawia makrostrukturę spoiny pachwinowej wykonanej podczas spawania stali 
Tablica I. Przebiegi prądu i napięcia spawania w funkcji czasu dla źródła klasycznego oraz wykonanych metodą MICOR

Table I. The graphs of welding current and voltage as a function of time for classical power source and modern solution based on the MICOR technology

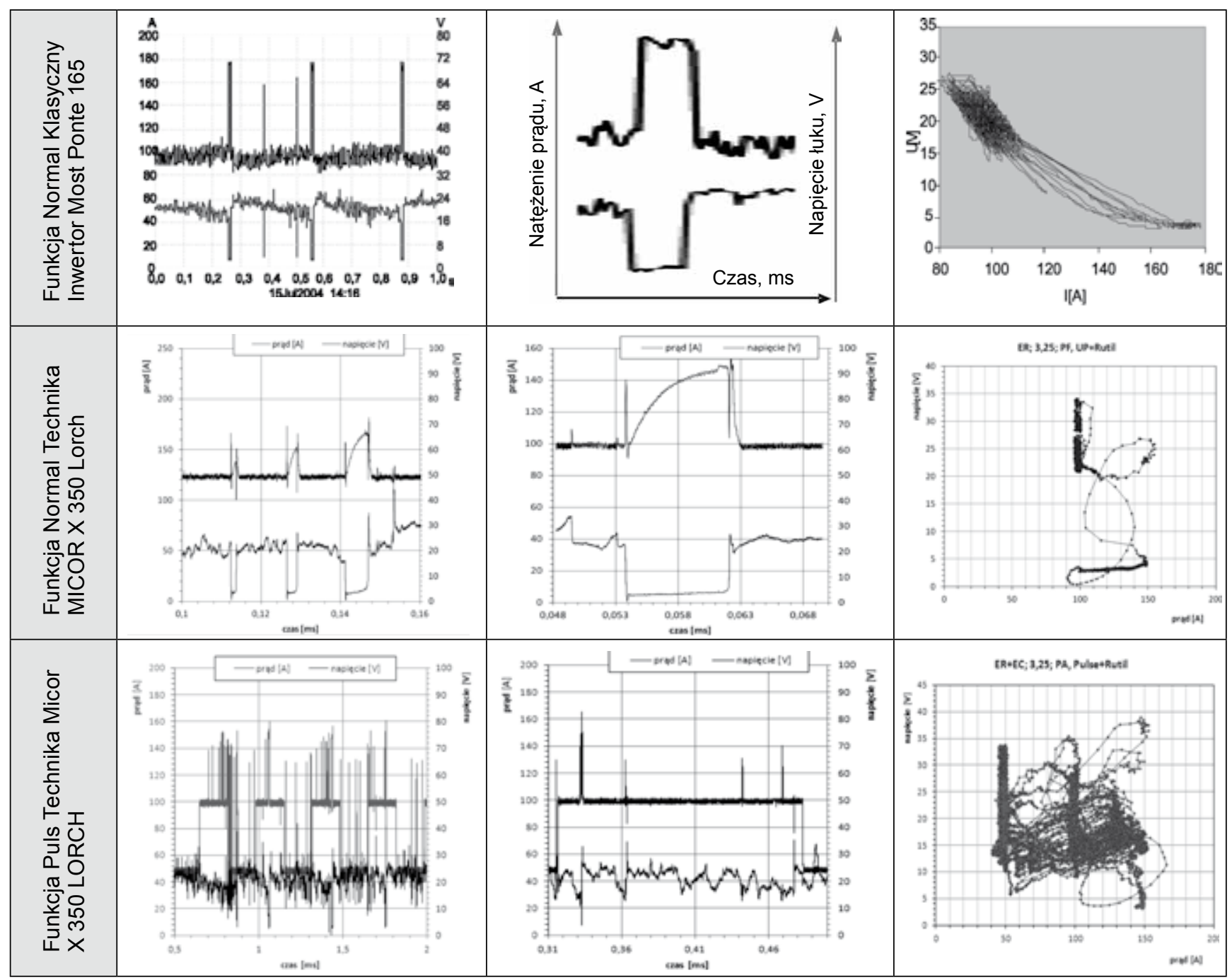

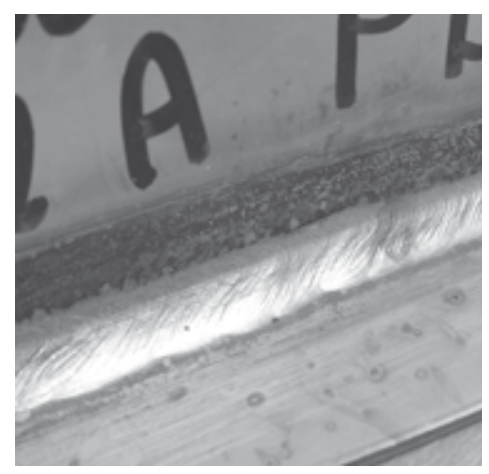

Rys. 6. Powierzchnia lica spoiny pachwinowej wykonanej w warunkach procedury normal z zastosowaniem źródła prądu opartego na technice MICOR

Fig. 6. The image of the face of fillet weld welded using normal procedure on the device with MICOR technology

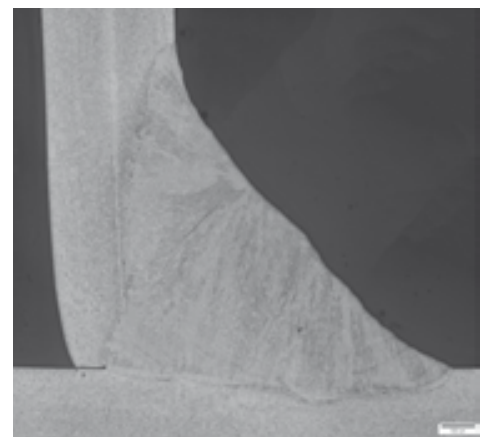

Rys. 9. Obraz mikrostruktury spoiny pachwinowej wykonanej $z$ impulsowym zasilaniem łuku z zastosowaniem źródła prądu opartego na technice MICOR

Fig. 9. The microstructure of fillet weld welded using Puls procedure on the device with MICOR technology

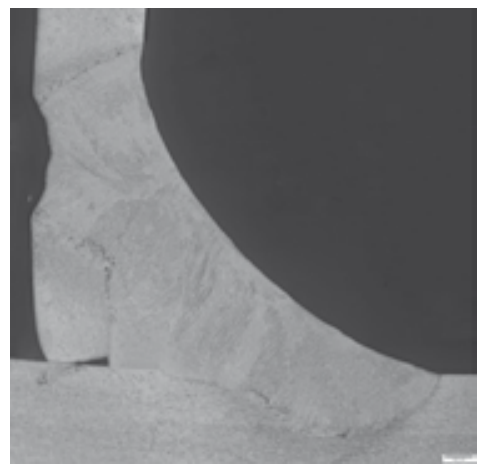

Rys. 7. Mikrostruktura spoiny pachwinowej wykonanej $w$ warunkach procedury normal z zastosowaniem źródła prądu opartego na technice MICOR

Fig. 7. The microstructure of fillet weld welded using normal procedure on the device with MICOR technology

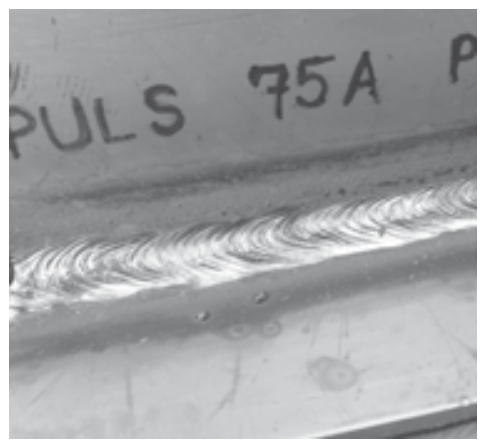

Rys. 8. Obraz powierzchni lica spoiny pachwinowej wykonanej $z$ impulsowym zasilaniem łuku z zastosowaniem źródła prądu opartego na technice MICOR

Fig. 8. The image of the face of fillet weld welded using Puls procedure on the device with MICOR technology 
nierdzewnej austenitycznej 1.4301 o grubości 2 mm z zastosowaniem urządzenia opartego na technice MICOR w trybie pracy normal. Jako materiał dodatkowy zastosowano elektrodę otuloną MOST 308L-16 (gat. 1.4316), którą stapiano z zastosowaniem prądu o wartości $75 \mathrm{~A}$. Na rysunku 9 przedstawiono makrozgład spoiny pachwinowej wykonanej z zastosowaniem tych samych parametrów, z impulsowym trybem pracy zasilacza (Puls).
Na podstawie badań stwierdzono dużo mniejsze odpryski podczas spawania z impulsowym zasilaniem łuku (Puls) w porównaniu ze spawaniem w trybie pracy zasilacza Normal. Zaobserwowano również dużo mniejsze odkształcenia blach po procesie spawania w trybie impulsowym, niż w procedurze Normal.

\section{Podsumowanie}

Rozwój nowoczesnych urządzeń spawalniczych wciąż trwa, szczególnie w odniesieniu do wyposażania ich w coraz nowsze tryby pracy. W ostatnich latach na rynku urządzeń spawalniczych pojawiło się kilka nowatorskich rozwiązań konstrukcyjnych źródeł ener-

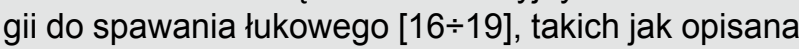

w artykule technika MICOR. Charakterystyczne są właściwości zasilaczy inwertorowych, których efekty w postaci wysokiej stabilności procesu spawania oraz znacznej (ok. 50\%) redukcji masy silnie wpływają na poszerzenie zakresu przydatności technologicznej zarówno samej metody MMA, jak i spawania w ogóle.

\section{Literatura}

[1] Chmielewski T., Golański D.: Znaczenie spawalnictwa w procesie remanufacturingu. Przegląd Spawalnictwa, 2011, nr 6, s. 29-32.

[2] Chmielewski T., Golański D.: Napawanie brązu berylowego stellitem metodą MCAW. Przegląd Spawalnictwa, 2011, nr 10 , s. $23-27$.

[3] Chmielewski T., Węglowski M.: Analiza rynku spawalniczego w Polsce pod względem sprzedaży urządzeń oraz materiałów spawalniczych. Przegląd Spawalnictwa, 2010, nr 6, s. 28-31.

[4] Kolasa A., Cegielski P., Michalis A.: Nowe krajowe wielofunkcyjne źródło energii elektryczne do spawania łukowego. Przegląd Spawalnictwa, 2002, nr 8-10.

[5] Węglowski M.: Badania właściwości spawalniczych źródeł energii elektrycznej z wewnętrzną przemianą częstotliwości. Rozprawa doktorska, Warszawa, 2008.

[6] Dobaj E.: Maszyny i urządzenia spawalnicze. Wydawnictwa Naukowo-Techniczne, Warszawa, 1998.

[7] Kensik R.: Eksploatacja urządzeń spawalniczych. Część I. Źródła spawalnicze. Skrypt Politechniki Częstochowskiej, Częstochowa, 1995,

[8] Kolasa A.: Cyfrowa rewolucja w spawalnictwie. Przegląd Spawalnictwa, 1998, nr 10-11.

[9] Steigerwald R.L.: A Comparison of Half-Bridge Resonant Converter Topologies. APEC Proceedings, s. 135-144, March, 1987.

[10] Fisher R.A., Steigerwald R.L., Saj C.F.: A Frequency/PWM Controlled Converter with Two Independently Regulated Outputs. HFPC Proceedings, pp. 459 -471, May, 1989.

[11] Fisher K.D.T., Ngo, Kuo M.H.: A $500 \mathrm{kHz}, 250 \mathrm{~W}$ DC- DC Converter with Multiple Outputs Controlled by Phase-Shifted PWM and Magnetic Amplitiers. HFPC Proceedings, s. $100-110$, May, 1988.
[12] Carrera A.: Dynamic behaviour of D.C. arc welding generators for arc welding. Dok. MIS II-31-58.

[13] Kolasa A.: Właściwości dynamiczne źródeł energii elektrycznej do spawania łukowego oraz kryteria ich oceny. Praca naukowa Politechniki Warszawskiej, Warszawa, 1990.

[14] PN-EN 60974-1:2007: Sprzęt do spawania łukowego - Część 1: Spawalnicze źródła energii.

[15] Węglowski M., Chmielewski T., Kudła K.: Porównanie wybranych właściwości nowoczesnych spawalniczych inwertorowych źródeł energii przeznaczonych do spawania metodą MAG. 51. Naukowo-Techniczna Konferencja Spawalnicza, Dębe 22-24.10.2009.

[16] Węglowski M., Chmielewski T.: Efektywność spawania w odmianach metody MAG na podstawie wybranych właściwości spawalniczych. I Konferencja Polskiej Izby Producentów Urządzeń i Usług „Nowoczesne Technologie Obróbki Metali”, Bydgoszcz, 31.03 - 1.04. 2011.

[17] Węglowski M., Chmielewski T.: Badania właściwości urządzeń z wewnętrzną przemianą częstotliwości przeznaczonych do spawania metodą MAG. XVII Międzynarodowa Konferencja Spawalnicza Energetyków, Opole - Turawa, 20-23 kwietnia 2010.

[18] Węglowski M., Chmielewski T., Kudła K.: Porównanie właściwości spawalniczych inwertorowych źródeł energii przeznaczonych do spawania metodą MAG. Przegląd Spawalnictwa, 2009, nr 10, s. 81-83

[19] Węglowski M., Kudła K.: Porównanie klasycznych źródeł inwertorowych z inwertorami zbudowanymi w technice MICOR, 54 Naukowo-Techniczna Konferencja Spawalnicza „SPAWALNICTWO. OSIĄGNIĘCIA - POTRZEBY - WYZWANIA", Sosnowiec 16-18 października 2012, Biuletyn Instytutu Spawalnictwa, nr 5/2012.

[20] Katalog RYWAL-RHC, Wyd. 3, Toruń, 2011. 